\title{
ANALISA KEKUATAN TARIK DAN KEKERASAN TITANIUM ASTM B348 SETELAH MENGALAMI PROSES PENGELASAN DENGAN METODE FRICTION WELDING
}

\author{
INDRA SURYA ${ }^{1}$, FATHUR CAKRA DIWANTARA $^{2}$ \\ ${ }^{I}$ Mahasiswa Jurusan Teknik Mesin, Universitas Bandar Lampung \\ Program Studi Teknik Mesin, Universitas Bandar Lampung \\ Jl. Zainal Abidin Pagar Alam No.26, Labuhan Ratu, Kedaton, 35142, Bandar Lampung Indonesia \\ Indra.surya@ubl.ac.id \\ fathurcakra@gmail.com
}

\begin{abstract}
Abstrak
Pengelasan merupakan suatu proses penting di dalam industry. Salah satu Teknik pengelasan tanpa menggunakan logam tambahan adalah las gesek (friction welding). Las gesek (friction welding) merupakan Teknik pengelasan dengan cara menggesekan dua permukaan material dan suhu material yang dilas dalam kondisi lumer. Dalam proses las gesek salah satu material berputar dan dan material lainya diam, kemudian material yang tidak berputar di gesekkan pada material yang berputar dengan diberi penekanan sampai kedua material mencapai kondisi lumer lalu mesin dihentikan dan terjadi penyatuan material. Penelitian ini dilakukan untuk mengetahui nilai kekuatan Tarik dan kekerasan Titanium ASTM B348 setelah dilakukan pengelasan gesek dengan variasi waktu penekanan 4, 6, 8, 10, 12, 14, 16 detik. Hasil uji kekerasan dengan metode Rockwell diperoleh nilai kekerasan rata-rata area Haz adalah 12.4 dan rata-rata area las adalah 8.6 , sedangkan pada raw material adalah 19.8. hasil pengujian Tarik diperoleh ratarata kekuatan Tarik adalah 51.13 dan rata-rata pertambahan panjangnya adalah 39.22\%. Dari hasil uji kekerasan dan kekuatan Tarik yang dilakukan penelitian ini menunjukan bahwa Titanium ASTM B348 setelah dilakukan pengelasan gesek dengan variasi waktu pengelasan menunjukan penurunan nilai nkekerasan dan kekuatan tariknya dari raw material.
\end{abstract}

Kata kunci : Las Gesek, Titanium ASTM B348, Uji kekerasan, Uji Tarik. 


\section{PENDAHULUAN}

\section{Latar Belakang}

Teknik pengelasan telah banyak dipergunakan pada konstruksi mesin. Hal ini disebabkan karena mesin yang dibuat dengan teknik penyambungan menjadi lebih sederhana dalam proses pembuatannya. Pengelasan biasa dipergunakan untuk reparasi misalnya membuat lapisan keras pada perkakas, mempertebal bagian-bagian yang sudah aus, menyambung dua plat atau poros dan lain-lain. Karena itu rancangan las harus memperhatikan kesesuaian antara jenis material yang akan dilas dan metode yang digunakan dalam proses pengelasan, sehingga hasil dari pengelasan memiliki kekuatan sambungan yang bagus dan sesuai dengan yang diharapkan. Dalam hal ini dasarnya adalah efisiensi yang tinggi, biaya yang murah, penghematan tenaga dan penghematan energi.

Pengelasan di Indonesia sudah banyak dilakukan dengan berbagai macam jenis, tetapi ada juga yang jarang dilakukan yaitu pengelasan gesek atau dalam bahasa inggrisnya adalah friction welding. Dalam hal penelitian atau analisa, setelah proses pengelasan seorang ilmuwan biasanya akan melakukan berbagai macam jenis pengujian material fisik. Pada laporan penelitian ini, hasil pengelasan gesek akan dilakukan pengujian kekuatan tarik agar diketahui hasil kekuatan pengelasannya. Disamping itu juga dilakukan pengujian kekerasan mulai dari logam induk hingga bagian sambungan las. Sebelumnya, pengelasan gesek kali ini akan dilakukan dengan bantuan mesin bubut dan bahan uji terbuat dari Titanium. Rumusan permasalahan yang perlu dipecahkan kali ini adalah bagaimana agar dihasilkan kekuatan sambungan las antara dua titanium sehingga memiliki kekuatan sambungan yang baik dan kuat.

\section{Tujuan Penulisan}

Tujuan dari penelitian yang akan dilakukan adalah:

1. Mendapatkan kekuatan tarik setelah pengelasan menggunakan metode friction welding.

2. Mendapatkan kekerasan sambungan las pada titanium.

3. Mendapatkan pengaruh waktu dalam menghasilkan sambungan las berdasarkan pengujian yang dilakukan. 


\section{TINJAUAN PUSTAKA}

\section{Titanium}

Titanium merupakan logam yang berwarna abu-abu putih keperakan. Logam ini memiliki kerapatan 4510 $\mathrm{kg} / \mathrm{m}^{3}$, titanium berada diantara almunium dan stainless steel (termasuk dalam logam ringan). Meski ringan, logam ini mempunyai kekuatan hampir sama dengan baja, dan mempunyai daktilitas yang tinggi. Bentuk titanium yang dikomersilkan (kemurnian 99,2\%) memiliki ultimate tensile strength (UTS) sekitar 63.000 psi atau 434 Mpa. Logam ini memiliki kekerasan yang cukup tinggi, non-magnetik dan konduktor yang buruk. Selain itu, memiliki fatigue limit untuk batas pemakaian pada beberapa aplikasi. Logam ini memiliki titik leleh sekitar $1668^{\circ} \mathrm{C}$ dan titik didih $3287^{\circ} \mathrm{C}$ sehingga dapat dipakai sebagai logam refractori.

Sifat yang paling menonjol dari Titanium adalah ketahanan logam ini terhadap korosi hampir sama dengan platinum, logam ini mampu bertahan terhadap gas klorin, serangan asam, dan beberapa larutan garam. Titanium akan lebih tahan terhadap korosi apabila dipadukan dengan logam mulia seperti emas, perak dan platinum. Pada lingkungan dengan temperature yang tinggi, logam ini akan membentuk suatu lapisan pasif yang protektif.

\section{Pengelasan Gesek (Friction Welding)}

Pengelasan gesek (Friction Welding) adalah suatu metode pengalasan yang dilakukan untuk memperoleh hasil lasan dengan cara melakukan penggesekan pada ujung dua bahan las dengan menggunakan alat bantu mesin bubut. Las gesek termasuk jenis penyambungan padat (forging). Ditemukan atau dipatenkan oleh The Welding Institute pada tahun 1991. Pada pengelasan gesek, penyambungan terjadi oleh adanya panas yang ditimbulkan oleh gesekan akibat perputaran satu dengan yang lain antara logam-logam induk dibawah pengaruh gaya aksial. Kemudian salah satu diputar sehingga pada permukaan kontak akan timbul panas, bahkan mendekati titik didih logamnya, sehingga permukaan logam didaerah tersebut menjadi plastis. Dalam kondisi panas tersebut, pergerakan atau gesekan yang terjadi antar kedua logam dihentikan, kemudian di aplikasikan gaya tekan arah aksial, sehingga terjadi sambungan las gesek. Friction Welding atau las gesek ini banyak diaplikasikan pada dinding pesawat atau bodi pesawat. 


\section{METODOLOGI PENELITIAN}

\section{Diagram Alir}

Penelitian ini dapat digambarkan dalam diagram alir sebagai berikut :

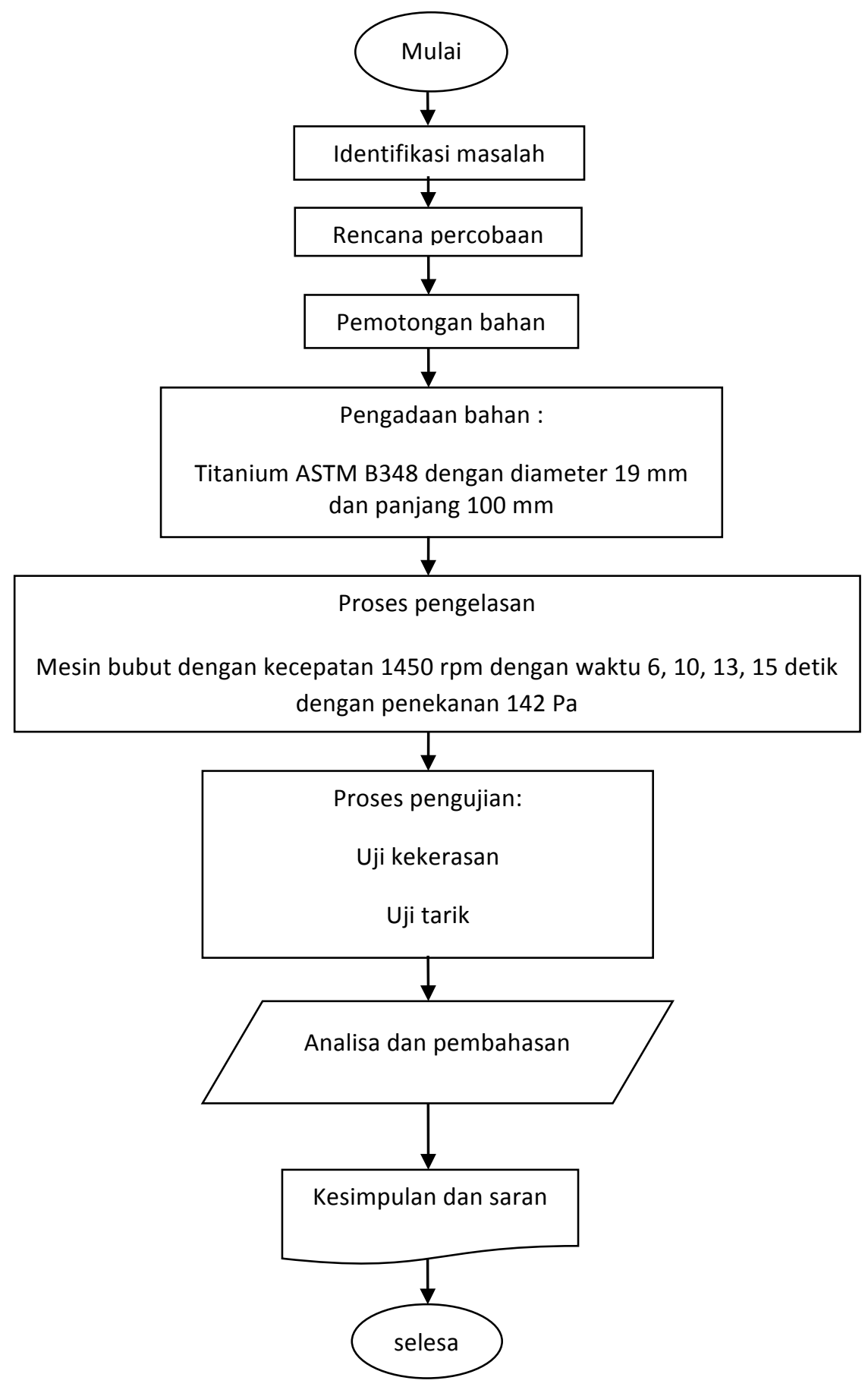




\section{Tempat Pelaksanaan}

a. Pembuatan spesimen dan pengelasan dilakukan di Laboratorium Teknik mesin Politeknik Negeri Semarang yang beralamatkan di Jl. Prof. Sudarto, Tembalang Kec. Tembalang, Kota Semarang, Jawa Tengah (50275)

b. Pengujian kekerasan dilakukan di Laboratorium Lembaga Ilmu Pengetahuan Indonesia (LIPI) yang beralamatkan di Gedung PPI Iptek LIPI, Jl.Raya Bogor km.47, Cibinong 16912, Bogor, Jawa Barat.

c. Proses pembubutan spesimen Pengujian dilakukan Di KLM Speed yang beralamatkan di Gg. Kencana No.33, Gn Sulah, Way Halim, Kota Bandar Lampung (35136)

d. Pengujian Tarik dilakukan di Laboratorium Lembaga Ilmu Pengetahuan Indonesia (LIPI) Balai Penelitian Teknologi Mineral (BPTM) yang beralamatkan di Jl. Ir. Sutami Km.15, Tanjung Bintang, Lampung Selatan (35361)

\section{Prosedur Kerja}

Prosedur pengelasan pada penelitian ini adalah :

a. Mempersiapkan mesin las Gesek.

b. Mempersiapkan benda kerja pada mesin las gesek untuk melakukan pengelasan.

c. Memasukkan waktu yang telah ditentukan pada panel yang tersedia pada mesin.

d. Melakukan proses penyambungan dengan friction welding dengan mencatat kecepatan dan tekanan yang ditentukan.

e. Mesin memutar benda kerja kemudian proses pengelasan terjadi pada saat benda kerja yang tidak berputar dikontakkan dengan benda kerja yang berputar sampai kedua permukaan membentuk sambungan las dan kemudian putaran berhenti dan terjadi proses penyatuan material.

f. Proses selesai, spesimen dipindahkan dari mesin las Gesek. 


\section{HASIL DAN PEMBAHASAN}

\section{Hasil Uji Kekerasan}

\begin{tabular}{|c|c|c|c|}
\hline No & Spesimen & Rata-rata Haz & Rata-rata Las \\
\hline 1 & sambungan (4 detik) & 14 & 2,8 \\
\hline 2 & sambungan (6 detik) & 16,5 & 11,0 \\
\hline 3 & sambungan (8 detik) & 13,8 & 6,8 \\
\hline 4 & sambungan (10 detik) & 9,7 & 8,5 \\
\hline 5 & sambungan (12 detik) & 12,1 & 12,3 \\
\hline 6 & sambungan (14 detik) & 12,7 & 12,9 \\
\hline 7 & sambungan (16 detik) & 8 & 8,6 \\
\hline 8 & Rata-rata sambungan 1-7 & 12,4 & \\
\hline & & & \\
\hline
\end{tabular}

\section{Tabel Hasil Uji Kekerasan}

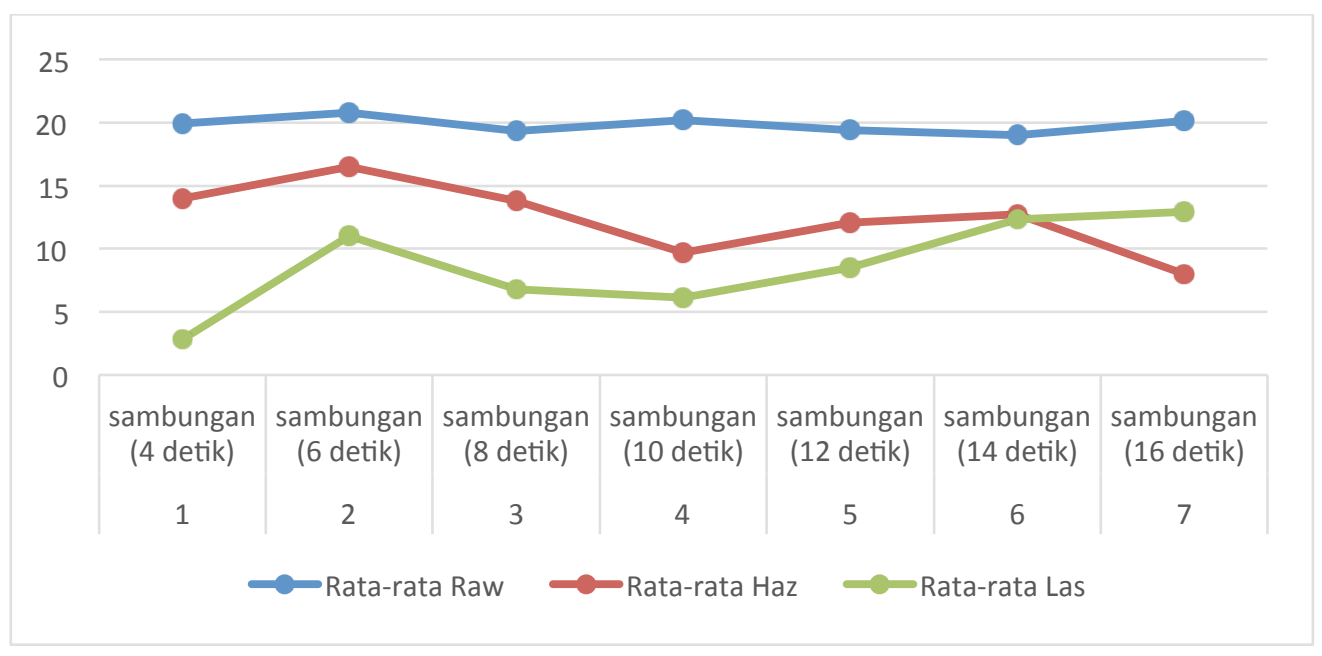

\section{Grafik Uji Kekerasan}

Dari data diatas, diperoleh nilai rata - rata haz sambungan 1 - 7 adalah 12.4 dan nilai rata rata las sambungan 1 - 7 adalah 8.6 ,sedangkan nilai haz tertinggi pada sambungan las terdapat pada spesimen 2 (6 detik) dengan nilai 16.5 dan haz terendah pada spesimen 7 (16 detik) dengan nilai 8 , sedangkan untuk daerah las tertinggi terjadi pada spesimen 7 (16 detik) dengan nilai 12.9 dan nilai las terendah terjadi pada spesimen 1 (4 detik) dengan nilai 2.8 . 
Data hasil pengujian kekerasan menunjukkan Titanium ASTM B348 setelah dilakukan pengelasan gesek dengan variasi waktu 4 detik, 6 detik, 8 detik, 10 detik, 12 detik, 14 detik, 16 detik mengalami kenaikan dan penurunan nilai kekerasan pada daerah haz dan las nya, namun nilai nya masih dibawah raw material. Pada sambungan spesimen 2 (6 detik), spesimen 3 ( 8 detik), spesimen 4 (10 detik) mengalami penurunan nilai haz namun pada sambungan spesimen 5 (12 detik) ke spesimen 6 (14 detik) mengalami kenaikan dan mengalami penurunan kembali pada spesimen 7 (16 detik) digambarkan pada grafik gambar 4.1. sedangkan untuk daerah las, pada sambungan spesimen 2 (6 detik) mengalami penurunan sampai ke spesimen 4 (10 detik), lalu pada sambungan spesimen 5 (12 detik) terus mengalami kenaikan sampai spesimen 7 (16 detik) dapat dilihat pada Grafik gambar 4.1

Kenaikan dan penurunan nilai kekerasan area pengelasan haz dan las pada sambungan las gesek terjadi karena pada Titanium ASTM B348 terdapat unsur carbon (C) sebesar $0.08 \%$ sehingga dapat mempengaruhi nilai kekerasan pada spesimen. Pengaruh waktu pada proses pengelasan juga berdampak pada nilai hasil kekerasan dan kekuatan Tarik, jadi karena semakin lama proses pengelasan maka spesimen Titanium ASTN B348 akan semakin lembut disebabkan nilai unsur carbon yang mengalami penuruan yang menghasilkan nilai kekerasan pada area haz dan las lebih rendah dari raw materialnya.

\section{Hasil Uji Kekuatan Tarik}

\begin{tabular}{|c|c|c|c|}
\hline \multirow{2}{*}{ No } & Spesimen & Kekuatan Tarik & Pertambahan \\
& & Rata-rata & panjang \\
\hline 1 & sambungan (4 detik) & 50.15 & rata-rata (\%) \\
\hline 2 & sambungan (6 detik) & 50.27 & 39.56 \\
\hline 3 & sambungan (8 detik) & 51.96 & 40.69 \\
\hline 4 & sambungan (10 detik) & 50.79 & 40.12 \\
\hline 5 & sambungan (12 detik) & 52.61 & 42.17 \\
\hline 6 & sambungan (14 detik) & 52.86 & 41.19 \\
\hline 7 & sambungan (16 detik) & 49.32 & 38.08 \\
\hline 8 & Rata-rata sambungan 1-7 & 51.13 & 39.22 \\
\hline & & & \\
\hline
\end{tabular}

Tabel Hasil Uji Kekuatan Tarik 


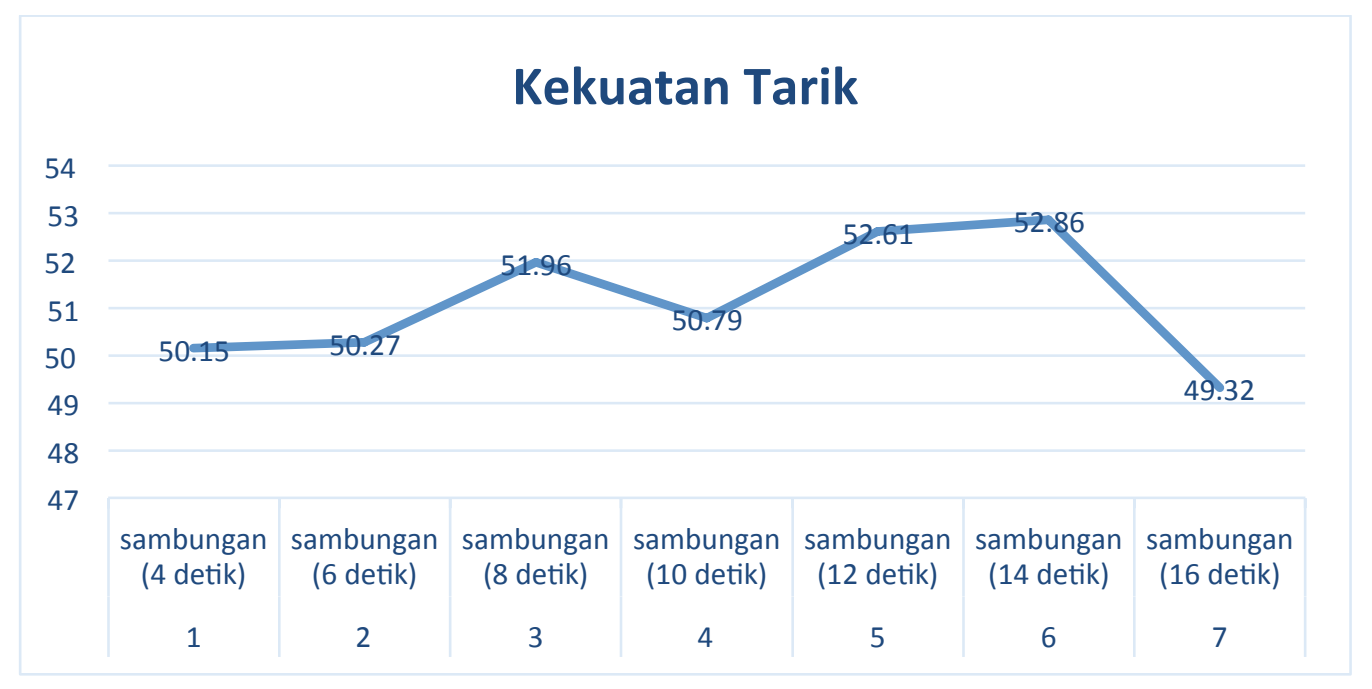

\section{Garfik Hasil Uji Kekuatan Tarik}

Hasil uji tarik setiap spesimen pada masing -masing spesimen mengalami bentuk patahan yang berbeda material mengalami perpatahan ulet (ductile fracture) karena sebelum patah mengalami pertambahan Panjang. Ciri dari perpatahan ulet adalah adanya pertambahan panjang, adanya bentuk retak pada patahan, dan permukaan nya kasar. Patah ulet juga terjadi pada seluruh sambungan spesimen $1-7$.

Jika dilihat pada grafik gambar 4.2 terjadi kenaikan nilai kekuatan tarik dari sambunagn spesimen 1 (4 detik), spesimen 2 ( 6 detik), dan spesimen 3 (8 detik), namun pada sambungan spesimen 4 (10 detik) mengalami penurunan dan pada spesimen 5 (12 detik) ke spesimen 6 (14 detik) mengalami kenaikan lagi. Nilai kekuatan tarik terbesar terjadi pada sambungan spesimen 6 (14 detik). Perbedaan bentuk sambungan dan kekuatan tarik ini disebabkan pengaruh waktu pengelasan dan pemasangan spesimen pada alat benda kerja pada proses pengelasan. 


\section{PENUTUP}

\section{Kesimpulan}

Dari pengujian kekerasan dan kekuatan Tarik pada pengelasan dengan metode friction welding yang telah dilakukan dapat di analisa :

a. Hasil uji kekerasan Rockwell dengan beban $150 \mathrm{~kg}$, menunjukkan nilai rata - rata kekerasan pada daerah las adalah 8.6, pada haz adalah 12.4, sedangkan pada raw material nilai kekerasan nya adalah 19.8, ini menunjukkan bahwa nilai kekerasan pada daerah las dan haz lebih rendah dari nilai kekerasan pada raw material. Perlakuan panas akibat gesekan pada saat proses pengelasan berpengaruh pada hasil kekerasan pada area las yang menyebabkan hasil kekerasan area las lebih rendah dari hasil area haz.

b. hasil kekuatan Tarik rata - rata sambungan spesimen 1 sampai 7 adalah $51.13 \mathrm{Kgf} / \mathrm{mm}^{2}$, ini menunjukan nilai kekuatan Tarik sambungan las mengalami kenaikan dan penurunan pada setiap sambungan spesimen uji. Dari data hasil analisa dapat disimpulkan bahwa semakin lama waktu pengelasan akan berpengaruh pada kekuatan tarik yang semakin rendah pada spesimen pengelasan Titanium ASTM B348.

c. Hasil pengujian kekerasan dan pengujian tarik menunjukkan bahwa Titanium ASTM B348 setelah dilakukan pengelasan dengan metode friction welding dengan variasi waktu pengelasan 4 detik, 6 detik, 8 detik, 10 detik, 12 detik, 14 detik dan 16 detik mengalami kenaikan dan penurunan nilai kekerasan dan kekuatan tarik nya.

d. Pada pengujian dan analisa hasil penelitian ini nilai kekerasan area haz optimal terjadi pada sambungan dengan waktu pengelasan 6 detik dan nilai kekerasan area las optimal terjadi pada sambungan dengan waktu pengelasan 16 detik, sedangkan nilai kekuatan tarik terbaik terjadi pada sambungan dengan waktu pengelasan 14 detik.

\section{Saran}

Dari penelitian dan analisa yang telah dilakukan, maka penulis menyarankan :

a. Untuk penulis selanjutnya disarankan agar memperbanyak jumlah spesimen las guna mendapatkan hasil pengujian yang lebih optimal.

b. Untuk penulis selanjutnya disarankan jika memungkinkan untuk melakukan pengujian struktur mikro agar mengetahui perubahan struktur material pada spesimen las dengan metode friction welding. 


\section{DAFTAR PUSTAKA}

Van Vlack. Lawrence H,1992, Ilmu Dan Teknologi Bahan, Erlangga, Jakarta.

Sofyan. Bondan T, 2011, Pengantar Material Teknik, Salemba Teknik.

Daryanto. Suwardi, 2018, Teknik Fabrikasi Pengerjaan Logam, Gava Media, Yogyakarta

Alip Mochamad, 1989, Teori Dan Praktek Las, Jakarta : Ditjen Pendidikan Tinggi.

Satoto, Ibnu, 2002, Kekuatan Tarik, Stuktur Mikro, Dan Struktur Makro Lasan Stanless Stell Dengan Las Gesek (Friction Welding), Universitas Muhammadiyah, Yogyakarta. 